\title{
Technical note: Emission mapping of key sectors in Ho Chi Minh city, Vietnam using satellite derived urban land-use data.
}

Nguyen Thi Quynh Trang et al

5 Correspondence to: Nguyen Thi Quynh Trang (ntqtrang@sti.vast.vn)
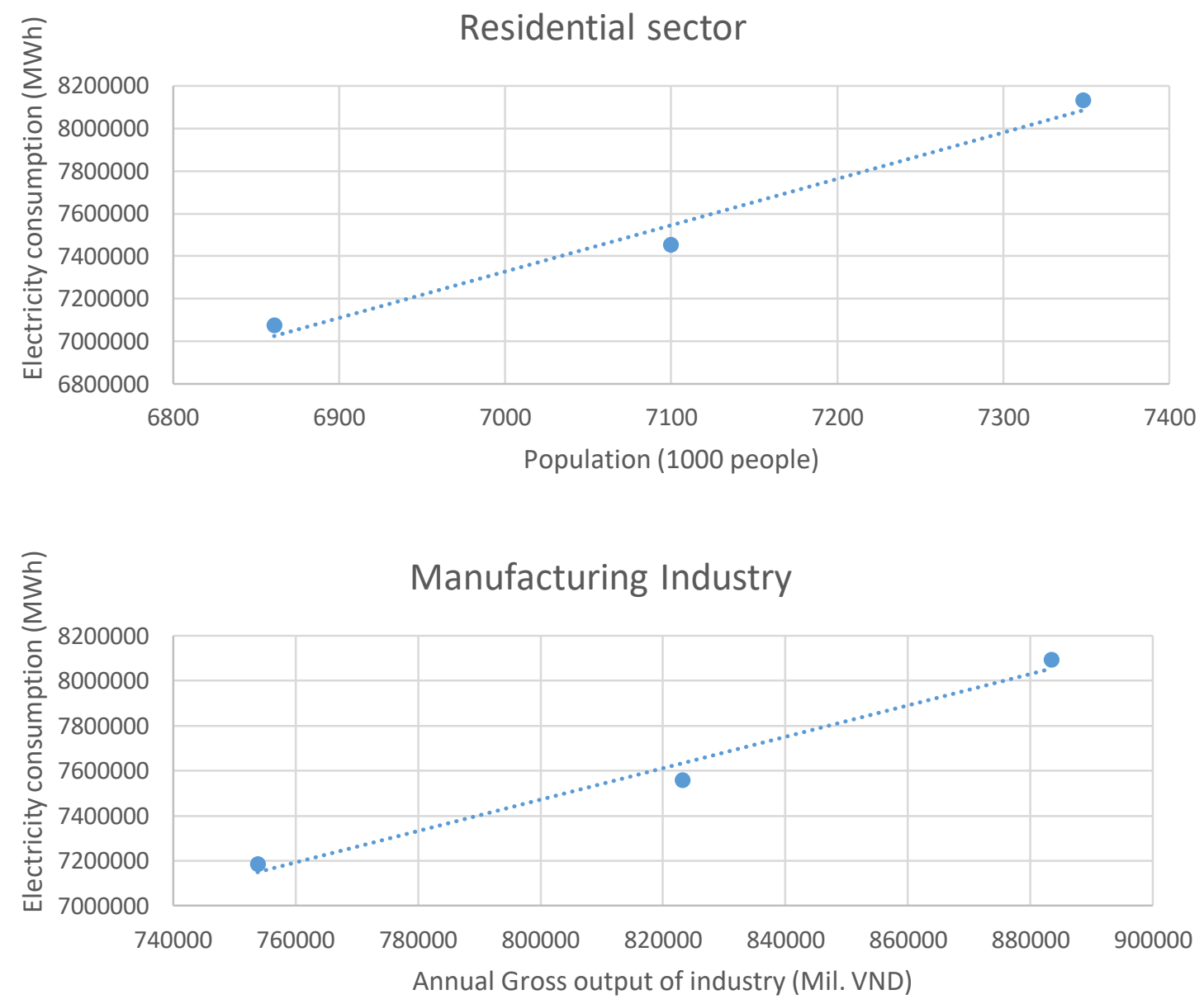

Figure S1. Correlations between electricity consumptions of Residential sector with Annual population in HCM and electricity consumptions of Manufacturing industry sector with Annual gross output of industry in HCM. 
Table S1. Description about REAS v2.1 inventory (J. Kurokawa et al., 2013)

\begin{tabular}{ll}
\hline Spatial resolution & $0.25 \mathrm{deg}$ \\
\hline Temporal resolution & Monthly \\
\hline Time domain & $2000-2008$ \\
\hline Species & SO2, NOx, CO, NMVOC, PM10, PM2.5, BC, OC, NH3, CH4, N2O, and CO2 \\
\hline Coverage & East, Southeast, South, and Central Asia. Asian part of Russia (Far East, Eastern and \\
& Western Siberia, and Ural) \\
\hline Sectors & Stationary combustion and industrial processes, road transport, Agricultural activities, \\
& Other sources. \\
& Power plant, industry, road transport, aviation, International navigation, other \\
& transport, domestic and other
\end{tabular}

Table S2. Data sources used in REAS2.1 for Transportation, Industry and Domestic sectors (J. Kurokawa et al, 2013)

\begin{tabular}{lll}
\hline \multicolumn{1}{c}{ Sector } & \multicolumn{1}{c}{ Transportation } & \multicolumn{1}{c}{ Industry and Domestic } \\
\hline Activity data & Vehicle numbers, annual distance traveled. & Fuel consumption or amount of industrial \\
& Vehicle numbers were from the World Road & product (for industrial process emissions). \\
& Statistics (IRF, 2006-2010) and then subdivided & Energy consumption data for each fuel type \\
& into vehicle types by using the national and sub- & including biofuels and sector categories were \\
& regional statistics and database of the GAINS & taken from the International Energy Agency \\
& model & (IEA) Energy Balances database.
\end{tabular}

